\title{
Counselling services in general practice
}

\section{The neөd for evaluation}

\author{
Michael B. King
}

Psychiatry and general practice have much in common; doctors manage patients presenting with vague complaints, cope with uncertainty and use psychotherapeutic skills. About $14 \%$ of consultations in family practice are wholly or largely for psychological reasons. A further 7 to $10 \%$ are also for psychological reasons but are not perceived as such by the doctor. Only one in 20 patients recognised as having psychological difficulties is referred to the secondary care services. This cautious approach is justified as many emotional problems managed in general practice are self-limiting adjustment reactions with a high rate of spontaneous resolution.

Traditionally, family doctors managed most of their patients' emotional problems. Marital strife, work problems, bereavement and behaviour problems in children, were all a part of day-today practice. In the past ten years, however, there has been such an expansion of counselling services in British general practice that currently one third of practices in England and Wales have a counsellor with no other task within the practice (Sibbald et al, 1993). Counsellors have emerged as a profession with their own organisations, codes of ethics and recommended methods of working (Gray, 1988). This has led to the suggestion that general practitioners (GPs) may need to be trained to counsel their patients (Rowland \& Maynard, 1989), a proposal which has been regarded with some scepticism (Shepherd, 1989). A government White Paper, Promoting Better Health led to increased opportunities for other professionals to work in general practice with funding becoming available for part reimbursement of salaries of a wider range of practice staff. Although many family health service authorities were prepared to pay for counsellors, the advent of specially funded health clinics as part of the new contract for GPs resulted in even greater avallability of funds. The caution to avoid "promoting a large counselling service in general practice before establishing what benefit accrues from this service ..." (Martin, 1988) went largely unheeded.
Although counsellors are welcomed by GPs, many doubts remain about the value of an expansion of their services in primary care. Until recently the training of a counsellor was poorly defined and anyone with a brief training in counselling skills could establish themselves as therapists. Family doctors had little concept of the nature of counselling or the skills to look for in engaging a suitable professional. This was remedied to some degree by the development of guidelines for the employment of counsellors in general practice (Counselling in Medical Settings, 1993) as well as by the system of accreditation monitored by the British Association of Counsellors.

Defining counselling is more difficult. A distinction is often made between counselling skills and counselling. Counselling skills are regarded as the ability to listen, empathise and reflect back to the client what the counsellor perceives he or she is saying. Counsellors adopt a neutral stance of 'supportive listening'. They refrain from giving advice and enable clients to gain insight and understanding rather than use the directives of others. Such skills are not only, however, the prerogative of counsellors; they are also used by other professionals such as doctors and teachers. If counselling is "more than the mere use of counselling skills" (Rowland, 1992) then what is it? The British Association for Counselling (1979), has declared that "... the task of counselling is to give the client an opportunity to explore, discover and clarify ways of living more resourcefully and towards greater well being". Rowland has defined it as "an ethical task in which the counsellor forms a therapeutic alliance with the client and uses a range of skills to facilitate the client's resolution of his or her problems" (Rowland, 1993). Put more simply, it is a talking therapy which aims to ease a person's discomfort, pain, distress or malfunctioning. Those who seek counselling are regarded as clients - customers who buy a service rather than patients who need help. This shift of emphasis has stemmed from a desire to 
avoid use of medical terminology and the history of a payment for service.

Given such difficulties of definition there have been two main approaches to the assessment of counselling in general practice. In much the more common one, the principles of audit are applied. A study is made of the numbers and backgrounds of the counsellors employed, types of clients seen, patterns of working with other members of the primary health care team and the management of issues of confidentiality and clinical responsibility. In the second, experimental conditions are applied in order to test a stated hypothesis about counselling.

Audit has revealed many difficulties with counselling attachments in British general practice. Counsellors come from widely different backgrounds, community psychiatric nurses and clinical psychologists outnumbering practice counsellors two to one. Many have minimal training in any form of psychotherapy and patients referred are often beyond their skills (Sibbald et al, 1993). This is not necessarily the fault of doctors or counsellors, rather it may result from the lack of an effective psychiatry service (King et al, 1993). Audit of process and outcome has mainly concerned psychologists working in primary care; patients appear to approve of the interventions and reductions occur in attendance rates and prescribing of psychotropic drugs. There is little in the way of published audit of the work of counsellors.

Experimental work is also uncommon. Several controlled trials in general practice have involved psychologists, but it is far from certain that their work should be regarded as counselling. Controlled trials of counselling have been hindered by poor recruitment, difficulties in randomisation and excessive drop-out rates and results have been equivocal. Although a counselling intervention by health visitors was reported as efficacious for women with post-partum depression, subjects were followed up for just 13 weeks (Holden et al, 1989). In a recent controlled study in general practice, Gournay \& Brooking (1992) reported no differences in outcome between patients with neurotic disorders randomised to receive counselling from a community psychiatric nurse or routine care from the GP. Several methodological problems were encountered, however, including a 50\% drop-out from the study.

How can measurement of the efficacy of counselling be tackled? Evaluation of outcome of a heterogeneous group of conditions treated in a variety of ways is far from easy. How can behaviour change be appraised alongside increased insight and feelings of well being? Although controlled research is feasible (King et al, 1993), the current popularity of counselling makes a randomisation procedure which bars half of participants from the counselling intervention less acceptable to patients and GPs. Doctors are becoming reluctant to offer 'routine' treatment to patients randomised to their care in a controlled trial. In some senses they have been de-skilled as counselling has grown in professionalism and mystique. Unfortunately, this tension is increasing the difficulty of conducting classical controlled trials. The prevailing passion for measurement of economic factors in the assessment of a treatment such as counselling is also assuming such importance that it is in danger of alienating subjects who may object to close enquiry about their financial affairs.

In a definitive, controlled trial patients should be randomised in a stratified manner, according to severity, after initial face-to-face assessments have been made. Counsellors taking part should have a recognised training of accreditable standard and preferably be employed for the trial to ensure uniformity of approach and avoid long waiting lists. In practices where a counsellor is already in place, the arrival of a research counsellor may provide a welcome opportunity to shorten the waiting list. Some groundwork may have to be done, however, to ensure that the 'research' counsellors are integrated into the practices and accepted by the participating doctors. There needs to be a consensus on outcome measures that will enable direct comparison between studies. Blind assessments of outcome are desirable but are not always feasible and reliance on patient self-report is important.

With the current redistribution of health service resources from secondary to primary care services, funds are increasingly available to expand the roles of the primary care team. Counsellors may well be a beneficial addition to the team, but before their services are further expanded there is an urgent need to assess where they are best placed, how issues of confidentiality can be addressed, which patients benefit and after how much treatment. Above all, we must know whether counselling 'works'. Within the limitations of our current methods, only controlled evaluations will provide a measure of the efficacy of counselling in this setting.

\section{References}

BRITSH ASSOCIATION FOR COUNSELLING (1979) Counselling: definition of terms in use with expansion and rationale. Rugby: British Association for Counselling.

Counselling in Medical SetTings (1993) Guidelines for the Employment of Counsellors in General Practice. Rugby: British Association of Counselling.

GOURNAY, K. \& BROOKING, J. (1992) An Evaluation of the Effectiveness of Community Psychiatric Nurses in Treating Patients with Minor Mental Disorders in Primary Care. Report to the Department of Health. London.

GRAY, D. (1988) Counsellors in general practice. Journal of the Royal College of General Practitioners, 38, 50-51. 
Holden, J.M., SAgovsKY, R. \& Cox, J.L. (1989) Counselling in a general practice setting: controlled study of health visitor intervention in treatment of postnatal depression. British Medical Journal. 298, 223-226.

KING, M.. BROSTER, G.. LLOYD, M. \& HORDER, J. (1994) Controlled trials in the evaluation of counselling in general practice. British Journal of General Practice (in press).

MARTIN, E. (1988) Counsellors in general practice. British Medical Journal, 297, 637.

ROWLAND, N. (1992) Counselling and counselling skills. In Counselling in General Practice. (ed. M. Sheldon) Exeter: Royal College of General Practitioners.

- (1993) What is counselling? In Counselling in General Practice (eds R. Corney \& R. Jenkins) London: Routledge.
- \& MAYNARD, A. (1989) Can general practitioners counsel? Journal of the Royal College of General Practitioners, 39. 118-120.

SHEPHERD, S. (1989) Can general practitioners counsel? Journal of the Royal College of General Practitioners. 39. 304.

SibBAld, B., AdDington-HALL, J., BRENNEMAN, D. \& Freeling. P. (1993) Counsellors in English and Welsh general practices: their nature and distribution. British Medical Journal, 306, 29-33.

Michael B. King, Sentor Lecturer and Honorary Consultant, Royal Free Hospital School of Medicine, Rowland Hill Street, London NW3 2QG

\section{MERCK ESSAY PRIZE}

\section{PDI7E $\$ 300$ and publication of winning essay in the Psychiatric IST PRILE Bulletin of the Royal College of Psychiatrists}

Two runner up prizes of $\$ 100$ each. All entrants will receive a book token.

All trainee psychiatrists (Senior House Officers, Registrars or Senior Registrars) in the United Kingdom and Republic of Ireland are invited to submit a 2000-3000 word essay on the topic:

\section{"Resistant Depression - Causes \& Consequences"}

Closing date for entries 31st March 1994

Sponsored by E. Merck Pharmaceuticals (A division of Merck Ltd.)

Further detalk from:

The Dean

Royal College of Psychiatrists

17 Belgrave Square

London SWIX 8PG 